\title{
ESTUDOS CITOLÓGICOS NO GÊNERO ARACHIS
}

\author{
A. J. T. Mendes
}

\section{I - INTRODUÇÃO)}

Pretendendo executar um programa de melhoramento do amendoim, por hibridação, as Seç̧ões de Oleaginosas e de Genética da Divisão de Fxperimentação e Pesquisas (Instituto Agronômico) solicitaram que realizásemos uma investigação do número de cromossômios em diversas espécies - variedades da coleçấo aqui existente, a qual foi, há algum tempo, enriquecida com o material trazido do interior de Mato Grosso pelos colegas Otacílio Ferreira de Sousa e Athos de Sousa Lima. Durante a realização dos nossos trubalhos, recebemos ainda do Dr. F. C. Hoehne, Diretor do Instituto de Botânica de São Paulo, a quem agradecemos, sementes de espécies que não possuíamos e que foram incluídas na investigação.

Apresentamos, neste artigo, os resultados a que chegamos, comparando-os com o que já se havia publicado sôbre o assunto e discutindo a seguir, à luz dos conhecimentos atuais, o que se pode inferir sôbre a origem do amendoim enltivado.

\section{II - CLASSIFICAÇÃO BOTÂNICA DAS ESPECIES DE ARACHIS}

Quando do descobrimento do Brasil, em 1500, os portugueses aqui encontraram, nas culturas indigenas, uma leguminosa ainda não conhecida nos meios civilizados : o amendoim. Foi, portanto, posteriormente a essa da ta que se deu a sua disseminação pelo globo.

$O$ gênero foi estabelecido por Linneu em 1735, no Genera Plantarum (2). E a espécie Arachis hypogæa L., com numerosas variedades, que se cultiva, hoje, em todos os paises quentes ou temperados do mundo.

Já em 1857, porém, foram mencionadas na "Flora brasiliensis" 7 espécies e. de então para cá, várias outras furäin descritas.

Hoehne (8) fêz uma revisão do gênero Arachis, chegando à conclusão de que eram em número de "... onze as espécies válidas com algumas formas e variedades mais ou menos bem caraterizadas" ; porém o próprio autor teve dificuldade em estabelecer limites entre determinadas formas, sugerindo que, com o auxílio da genética, talvez se pudesse adotar ainda um melhor critério na determinação das espécies.

Posteriormente, o mesmo autor (9) classificou ainda uma espérie nova de modo que ao todo seriam 12 as espécjes válidas atualmente, de acôrdo com a relação seguinte : 
1. A. tuberosa Benth.

2. 1. guaranitica Chodat \& Hassler

3. A. Diogoi Hoehne

forma: typica Hochne

subglabrata Hoehne

sericeo-villosa Hoehno: submarginata Hoehne minor Hochne

sub espécie : major Hoehne

4. A. angustifolia (Chodat \& Hassler) Killip

5. A. helodes Mirt.

6. A. villosa Benth.

7. 1. villosulicarpa Hoehne

8. 1. prostrata Benth.

sub espécie : Hagenbeckii (Harms) Hoehne

!). A. mearginata Gardn.

forma: submarginata Hochne

10. A. nambiquarae Hochne

11. A. hypogza L.

forma : typica Hoehne macrocarpa A. Chev.

12. A. glabrata Benth. microcarpa A. Chev.

Lorma: typica Hoehne major Hoehne minor Hoehue

\section{III - RESUMO DAS PESQUISAS CITOLÓGICAS JA REALIZADAS}

Fazendo referência a uma tese, não publicada, de Badami (1), Husted (13) informa que o número somático de $\mathbf{2 n}=\mathbf{2 0}$ cromossômios havia sido determinado em dois tipos eretos ("Spanish" e "Small Japan") e o de $\mathbf{2 n = 4 0}$ em um tipo rasteiro ("Virgínia"), todos pertencentes a $A$. hypogra I. Porém, Husted $(11,12,13,14)$ contou cromossômios em mais de uma centena. de plantas pertencentes a diversas variedades dessa mesma espécie, incluindo não só as duas cstudadas por Badami, como híbridos entre os tipos ereto (' rasteiro, verificando sempre $2 \mathbf{n}=\mathbf{4 0}$. Além de $A$. hypogæa L., também têm $2 \mathrm{n}=\mathbf{4 0}$ cromossômios as espécies $A$. nambiquaræ Hoehne e $A$. rasteiro Chev. (?) $(11,12,13,14)$. Ghimpu (5) determinou $2 \mathrm{n} \pm 40$ em $A$. hypogxa I. var. microcarpa Chev. em A. prostrata Benth. var. rasteiro.

Fazendo-se abstração de um único caso de aneuploidia $(2 n=41+1$ fragmento) encontrado por Husted (13) $\mathrm{cm}$ uma planta da espécie A. rasteiro Cher. (?), podemos dizer que tôdas as espéciess e variedades de Amendoim até lá pouco estudadas têm $\mathbf{2 n}=\mathbf{4 0}$ cromossômios.

A determinação de Badami não encontrou ronfirmação ulterior. Ele próprio (1) estudou híbridos naturais entre os tipos "Spanish" e "Big Japan" e realizou com sucesso hibridações entre "Small Japan" c "Virgínia", não constatando anomalias citológicas ou esterilidacle, o que mais uma vez confirma que se trata de tipos rom o mesmo número de cromossômios. A mesma confirmação é ainda dada pelas hibridações realizadas por Stokes. e Hull (20) entre a espécie $A$. nambiquaræ Hoehne e diversas variedades de A. hypogra L. incluindo entre estas as eretas e as rasteiras. 
O quadro 1 foi organizado através de uma revisão da literatura sôbre o assunto:

$$
\text { Q U A D R O } 1
$$

RESLMO DAS PESQL ISAS CITOLÓGICAS ANTERIORMENTH REALIZADAS

\begin{tabular}{|c|c|c|c|}
\hline ESPFCIES E VARIEDADES & $\mathrm{n}$ & $2 n$ & $A \mathrm{~L}$ T O R \\
\hline 1. hypogaa $\mathrm{L}$. & 20 & 40 & $\begin{array}{l}\text { Yamamoto, 192, } \\
\text { (Cit. por Husted, } \\
\text { 1936) }\end{array}$ \\
\hline
\end{tabular}

Kawakami, $\quad 1930$ (Cit. por Gaiser, 1933 e Husted, 1936)

A. hypogæa $L$. - tipos eretos :

"Small Japan"

"Small Japan"

"Spanish"

..

"Spanish"

Califórnia Long Red"

"Valência"

"Beni Tachikuki"

"The Pearl"

(Plantinlia amarela)

"Tennessec Red"

"Tative Chinese Peanut", ........ (F. P. I. n. ${ }^{\circ}$ 90.128)

"Pôrto Alegre" .............

"Amarelo"

"Oryu Tachikuki"

10

20

10

20

A. hypogre L. - tipos rasteiros :

"Virgínia"

.................

"Virgínia Bunch"

"Improved Virgínia" ...........

"Jumbo" . .................

"Basse" ..................

"Coinage" ".

"Senegal"

"Transvaal"

"Mauritus".

"Nagpur Groundnut n. 9" . . . .

"Fusekuki Dairyu"

"Foreign Plant Introd. n. 100833 " (da Bolívia)

"Nhambiquaras"

20

A. hypogæa L. - Híbridos :

"Red Spanish x Virginia Bunch" F2

"Runner x White Spanish" F1 ...

"White Spanish x Runner" F1 ...

"White Spanish x Runner" F4 ...

"Runner x Red Spanish" F1

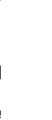

40

0

20

20

20

20

20

20

20

20

20

20

20

40

40

40

40

40

(40)

40

0

0

0

0

0

l3adami, 1928 (Cit. por Husted, 1936)

Husted, 1933, 1936

Badami, 1928 (Cit. por Husted, 1936)

Husted, 1931， 1936

Husted, 1931, 1936

Husted, 1931，1933

Husted, 1933

Husted, 1933, 1936

Husted, 1933

Husted, 1933

Husted, 1936

Husted, 1936

Husted, 1936

Husted, 1936

Badami, 1928 (Cit. por Husted, 1936)

Husted, 1931， 1933

Husted, 1931， 1933

Husted, 1931, 1936

Husted, 1933

Husted, 1933

Husted, 1933

Husted, 1933

Husted, 1933

Husted, 1936

Husted, 1936

Husted, 1936

Husted, 1936

Husted, 1936

Husted, 1936

Husted, 1936

Husted, 1936

Husted, 1936 


\begin{tabular}{|c|c|c|c|}
\hline ESPECIES E VARIEDADES & n & $2 n$ & $A \mathrm{I} T O \mathrm{R}$ \\
\hline A. hypogza L. var. microcarpa A. Chev. & & \pm 40 & Ghimpu, 1930 \\
\hline $\begin{array}{l}\text { A. prostrata Beth. var. rasteiro (Seg. } \\
\text { Chevalier é uma var. de } \mathbf{A} \\
\text { hypogæa) } \ldots \ldots \ldots \ldots \ldots \ldots \ldots\end{array}$ & & \pm 40 & Ghimpu, 1930 \\
\hline 1. "Nambiquarx Hoehme... & 20 & 40 & Husted, $1931: 1936$ \\
\hline A. rasteiro ('hev. (?). & 20 & 40 & Husted, $1931 \cdot 1936$ \\
\hline 1. rasteiro Chev. (?). & $20+\frac{1}{2}+1$ & $41+f$ & Husterl, 1936 \\
\hline
\end{tabular}

Apesar de não ter sido confirmada a existência de espécies diplóides, provas genéticas $(10,18)$ e citológicas $(12,13)$ fazem crer que as variedades de amendoim cultivadas são tetraplóides, e que um tipo ancestral diplóide deve existir. $O$ amendoinzeiro, hoje largamente cultivado en todos os paises quentes do mundo, tem sua origem no Brasil (Estado de Mato Grosso). segundo as pesquisas levadas a efeito principalmente por Chevalier (3) e por Hoehne (8). Onde, pois, senão no Brasil, deve ser procurado êsse ancestral diplóide?

\section{IV - MATERIAL}

Ao iniciarmos o nosso trabalho, interessava-nos apenas determinar o número de cromossômios em diversas variedades de A. hypogæa L., além de uma variedade denominada "amendoim bravo" e que se supõe tratar-se de A. prostrata Benth. Eram essas as variedades que as Secções de Genética e de Oleaginosas tencionavam empregar em seu plano de melhoramento ; 0 "amendoim bravo" apresentava um interêsse especial por ser resistente a moléstias e possuir alto teor em óleo e pericarpo fino, qualidades que se desejava transmitir às outras variedades.

Pelos resultados a que logo chegamos, no entanto, achamos que seriat interessante ampliar as investigações às espécies que poderiam constituir os ancestrais de $A$. hypogra L. Dirigimo-nos então ao Dr. F. C. Hoehne, Diretor do Instituto de Botânica de São Paulo, que, solìcitamente, atendeu ao nosso pedido, enviando-nos sementes de $A$. marginata Gardn., A. marginata Gardn. var. sub-marginata Hoehne, A. Diogoi Hoehne forma typica Hoehne e A. Diogoi Hoehne sub-espécie major Hoehne, além de $A$. nambiquaræ Hoehne (esta espécie é ìntimamente relacionada com $A$. hypogæa L.). Posteriormente, enviou-nos ainda o Dr. Hoehne sementes de uma nova espécie de Arachis, à qual denominara $A$. hirsuticarpa, mas que logo em seguida a descreveu (9) como $A$. villosulicarpa Hoehne. Com exceção de $A$. nambiquaræx, tôdas as outras são de introdução muito recente do Estado de Mato Grosso. 
O material trazido dêsse Fistado pelos colegas Otacílio Ferreira de Sousa e Athos de Sousa Lima ainda não foi classificado, sendo evidente, no entanto, que uma parte se enquadra perfeitamente no que se chama de $A$. nambiquaræ Hoehne.

\section{V- METODO}

As sementes foram postas a germinar em caixas de Petri, soble um papel de filtro umedecido; ao germinarem, cortavam-se algumas raíze: que eram fixadas imediatamente em "Craf" (19) e as mudas eram transplantadas para canteiro. Após a fixação, o material era deshidratado e incluído em parafina através de uma série de álcool etílico-álcool butílico ; os cortes eram feitos a 8 mirrons de espessura e coloridos pela hematoxilina férrica de Heidenhain.

As contagens do eromossômios eram leitas num microscópio "Zeiss", ao qual adaptamos uma orular "Leitz" de desenho; usando uma objetiva "Zeiss" 90x de imersão s uma ocular "Leitz" 20x, obtínhamos no plano de desenho um aumento do $2140 \mathrm{x}$. Das melhores figuras obtivemos microfotografias com luma râtmara "Contax". adtaptada ato microseópio, as" quais foram ampliadas convoniontemonts" (16) para guc se obtivessem os mesmos aumentos que nos desenhos. Algumas dat metáfases somáticas desenhadas ou fotografadas foram aproveitadas para ilustrar o furesente trabalho, sem alteração da escalia de'aumento.

\section{VI -.. RFSULTADOS OB'TIJ)S}

Das variedades que interessaram aos planos das Secçoes de Genética e Oleaginosas, cinco pertenciam à espécic $A$. hypogzea L. e eram tetraplóides $(2 \mathrm{n}=40)$; uma única, denominada "amendoin braro" e provàvelmente pertencente à espécies A. prostrata Benth., era diplóide $(2 n=20)$.

Das espécies originárias do Instituto do Botânie‘a, somente A. nambiquaræ Hoehne era tetraplóide $(2 n=40)$; as ontras 5 eram diplóides $(2 n=20)$ : A. marginata Gardn., 1. marginata Gardn. nar. submargincta Hoehne. A. Diogoi Hoehne f. typica Hoehne, A. Diogoi IIoehne sub-repéeie major Hoehne e A. villosulicarpa Hochne.

Das espécies ou variedades trazidas de Mato Grosiso pelo eng. agrônomo Otacílio F. de Sousa, duas pertencem, sem dúvida, à A. nambiquaræe e são tetraplóides $(2 \mathrm{n}=40)$; cinco outras, ainda não classificadas, tambén são tetraplóides $(2 \mathrm{n}=40)$; e apenas uma, que ainda não foi identificada, é diplóide $(2 \mathrm{n}=20)$.

Quanto ao material trazido pelo eng. agrônomo Athos de Sousa Lima, porém de una outra região do Estado de Mato Grosso, o mesmo ainda não foi por nós examinado.

O quadro 2 reune os resultados destas contagens: 
Q I I D R O 2

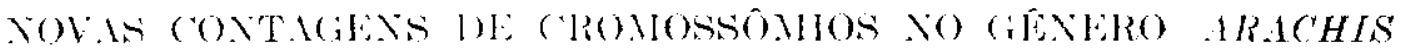

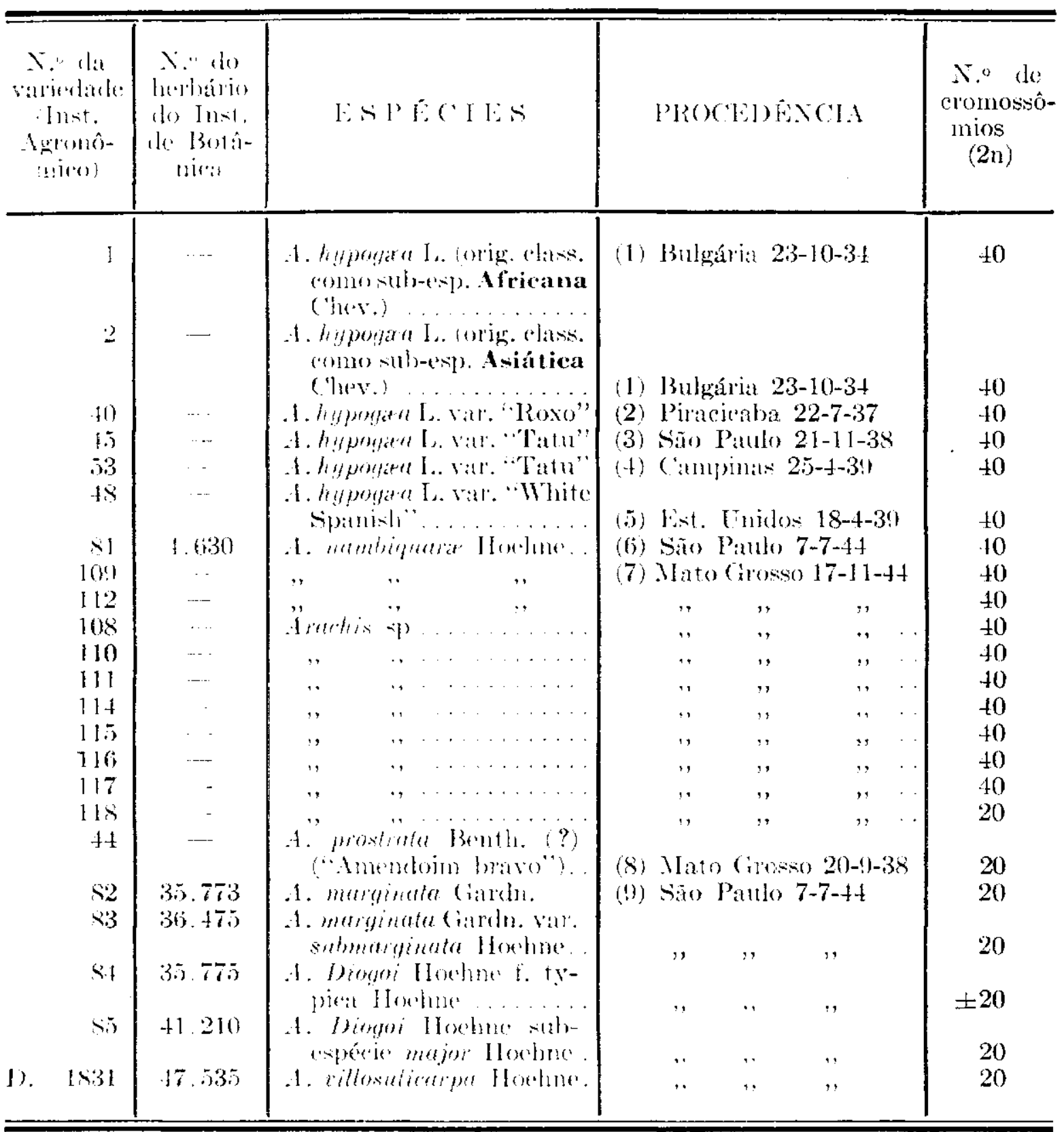

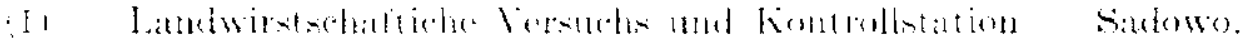

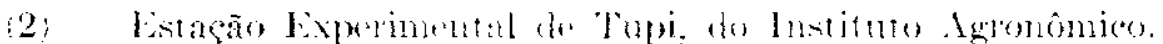

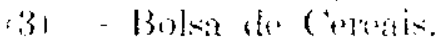

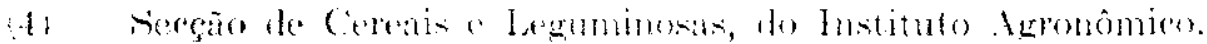

(5) Pon Haston Perant (o. Colúmbia, (itrirgia.

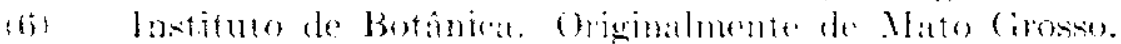

(7) Trazilate pelo I) (1) IS Sionsit.

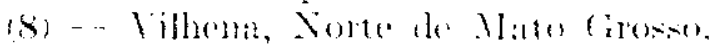

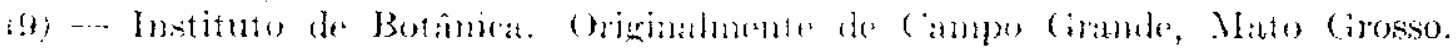

Uma quimera cromosionica foi constatada em Arachis hypogæa L. variedade "Tatu": uma raíz do natureza quase que totalmente tetraplóide 
normal apresentou-se com um setor de células maiores onde foi possível contar, muito bem, $\mathbf{8 0}$ cromossômios.

Conclui-se da presente investigação que existem atualmente formas diplóides e formas tetraplóides de Arachis. As variedades comerciais são tôdas tetraplóides ; as formas diplóides são encontradas em Mato Grosso, onde já se presumia que fôsse a terra de origem do amendoim.

Tendo viajado pelo nordeste de Mato Grosso, o eng. agrônomo O. F. de Sousa obteve dos índios cajabis (Região do Rio Paranatinga) sementes de várias formas de amendoim por êles cultivadas, tôdas tetraplóides, com exceção de uma diplóide (talvez não cultivada), o que parece demonstrar que se bem que existam na região em estado agreste plantas diplóides, os selvícolas dessa tribo preferem cultirar as formas tetraplóides. provàvelmente por sua produtividade.

\section{VII - ORIGEM DO AMENDOLM COMUM}

As numerosas variedades de amendoim hoje cultivadas pertencem tôdas à espécie Arachis hypogæa L., exceção feita à variedade "nhambiquara" que, diferindo bastante das outras sob vários aspectos, foi classificada por Hoehne como espécie distinta (A. nambiquaraz Hoehne).

Dadas as afinidades sistemáticas constatadas por Hoehne, êste autor (8) sugere que $A$. hypogæa L. tenha se originado de $A$. marginata Gardn. ou $A$. helodes Mart. ou ainda de um cruzamento destas duas espécies, "porque se carateriza como elas, pelos folíolos marginados com cílios moles". Sugere ainda que certos tipos da espécie "partiram do aproveitamento de $\boldsymbol{A}$. prostrata Benth" por se distinguiren "pelos folíolos mais oblongados e cá e lá ornados com cerdas em suas margens entre os cílios".

O exame citológico de A. marginata Gardn. e de A. prostrata Benth revelou que ambas são diplóides $(2 \mathrm{n}=20)$. Não possuímos material de $A$. helodes Mart., mas, baseando-nos na descrição feita por Hochne (8) e em sua estampa elucidativa, esta espécie parece pertencer ao grupo das espécies diplóides; o próprio Dr. Hoehne declara que por algum tempo a confundiu com a $A$. prostrata Benth.

A espécie Arachis hypogæa L. é tetraplóide $(2 \mathrm{n}=40)$ e pode realmente ter-se originado de uma das espécies citadas por Hoehne, ou de um híbrido entre estas espécies. O que fica claro, porém, é que sua formação se deu através de uma duplicação de cromossômios. Ela pode ser um autotetraplóide ou um alotetraplóide.

Sua origem é aparentemente recente, pois que as análises genéticas realizadas por Badami (1), Hayes (6), Patel et al (18) e Hull (10) demonstram a existência ainda de vários pares de gens em duplicata.

Tais análises genéticas mostram que as diferenças entro os tipos mais evidentes de plantas da espécie $A$. hypogæea L., tais como rasteiro e ereto, ramificado e simples, revestimento ou nâo por pêlos, côres rariadas das sementes etc. se devem a uns poucos fatôres genéticos ; "diferenças como 
essas (Patel et al 18) são encontradas entre as variedades em muitas espécies, e geralmente não se cogita de classificar tais variedades como sub-espécies nem de sugerir sua origem de duas diferentes espécies".

\section{VIII -.. O AMENDOIM DOS NHAMBIQUARAS}

Em 1918 excursionou pelo Fstado de Mato Grosso o botânico João Geraldo Kuhlmann, que trouxe determinadas sementes de Arachis, as quais foram cultivadas no Rio de Janciro e depois no Horto "Oswaldo Cruz", de São Paulo. O Dr. F. C. Hoehme (7) observou esta cultura durante dois anos, romparando-a com uma de Arachis hypogæa L., estabelecida a scu lado: verificon que se tratara de plantas mais robustas, cujos legumes e sementes excediam ao dôbro do tamanho dos do amendoinzeiro comum; além disso, as sementes apresentavam-se em geral bi-coloridas, podendo, no entanto, ser claras, amarelas, vermelhas e arroxadas. Por tudo isso, as novas plantas diferiam bastante das espécies já descritas, que gozam de "grande afinidade" e diferiam ainda do "amendoim comum", especialmente pela distribuição das flores e frutos até as extremidades dos ramos, os quais eram também mais prostrados c "muito mais ramulosos". Decidiu Hoehne classificar o novo material como pertencente a uma espécie nova, que denominou Arachis nambiquaræ Hoehne. Segundo suas próprias observações, cada planta produziria 50 a 100 legumes, os quais tinham, frequentemente, duas sementes a raramente uma só, podendo também ter mais de duas (8).

() "amendoim dos nhambiquaras" é cultivado por certa tribo de índios de Mato Grosso e, pela sua deseoberta, Hoehne (8) chega "à conclusão categórica e insofismável de que, nos processos práticos de agronomia, os ameríndios levavam e ainda levam - apesar de uma vida mais ou menos nômade -- reais vantagens ao homem civilizado que aqui aportou, porque êles tinham conseguido fazer de um grão de menos de $8 \mathrm{~mm}$ um de $35 \mathrm{~mm}$ e ainda o conservam assim a té o presente momento, enquanto os agrônomos e agricultores, recebendo tão boa semente em 1500, conseguiram reduzí-la para um tamanho que não excede ì metade do indicado".

Neme e Sampaio (17) publicaram dados referentes a uma experiêneia sôbre o rendimento relativo de diversas variedades de $A$. hypogxa L. cultivadas no Estado, e de A. nambiquare Hoehne, que citam apenas como "variedade Nhambiquara". Após 6 anos de cultura, esta varieciade e duas outras foram abandonadas como decididamente inferiores às restantes, em produtividade.

E suposição de Hoehne (8) que A. nambiquaræ Hoehne se tenha originado da espécie A. glabrata Benth.

Aquela espécic, no entanto, não apresenta dificuldade em se cruzar naturalmente com A. hypogra, pois o próprio Dr. Hochne, quando gentilmente nos cedeu sementes de $A$. nambiquaræ para o presente estudo, referiu- 
se às mesmas como "não mais perfeitamente puras". Através de hibridações artificiais entre as espécies em aprêço, Stokes e Hull (20) realizaram estudos genéticos constatando a existência de gens comuns a ambas. Isto mostra que $A$. nambiquaræ pode ter tido a mesma origem de $A$. hypogæa e até mesmo ser considerada como variedade desta última. Ambas. as espécies têm $2 n=40$ cromossômios e devem ter surgido pela duplicação dos cromossômios de uma das espécies diplóides ou de híbridos entre espécies diplóides.

\section{S U XI A R I O}

Tôdas as variedades de amendoim estudadas até o presente têm $\mathbf{2 n}=\mathbf{4 0}$ cromossômion e pertencem à espécie $A$. hypogæa L. e à $A$. nambiquaræ Hoelune.

$O$ autor do presente trabalho confirma essas contagens e revela a existência de espécies com $\mathbf{2 n}=\mathbf{2 0}$ cromossômios, a saber : $A$. prostrata Benth (?), A. marginata Gardn., A. marginata Gardn. var. submarginata Hoehne, A. Diogoi Hoehne f. typica Hoehne, A. Diogoi Hoehne sub-espécie major Hoehne e $A$. villosulicarpa Hoehne. Além disso, o número $2 \mathrm{n}=20$ foi encontrado em mais uma espécie não identificada e $2 \mathrm{n}=40 \mathrm{em}$ plantas de 7 grupos diferentes, cuja identificação também ainda não foi feita.

Uma quimera cromossômica foi constatada em raiz de $A$. hypogæa, parte com 40 e parte com 80 cromossômios.

O amendoim cultivado, à luz desta investigação e das provas genéticas constatadas por vários autores, deve ser encarado como tetraplóide e deve ter surgido espontâneamente no próprio centro de origem das formas diplóides (Estado de Mato Grosso).

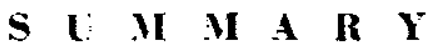

All the varieties of peanuts previously studied have been found to have $2 \mathrm{n}=\mathbf{4 0}$ chromosomes and belong to the species Arachis hypogrea L. and A. nambiquare Hoehne.

In the present paper the author confirms the chromosome number previously reported and reveals the existenre of other species of peamuts having $\mathbf{2 n}=\mathbf{2 0}$ chromosomes. The species having $2 \mathrm{n}=\mathbf{2 0}$ chromosomes were found to be: A. prostrata Benth (?), A. marginata Gardn., A. marginata Gardn. var. submarginata Hoehne, A. Diogoi Hoehne f. typira Hoehne, A. Diogoi Hoehne sub-esp. major Hoehne and A. villosulicarpa Hoehne.

In eight different samples of permuts seeds sent from the State of Mato Grosso, seven were found to have $\mathbf{2 n}=\mathbf{4 0}$ chromosomes and one sample had $\mathbf{2 n}=\mathbf{2 0}$ chromosomes. linfortunately it has not yet been possible to obtain the botanical classification of these peinut samples.

A chromosomal chinatera observed in a root tip section of A. hypogra showed sectors having 40 and 80 chromosomes.

Based upon the genetical studies made by several authors, and under the light of the present investigation, the cultivated peanut must be considered of a tetraploid nature. It seems like+ly that $A$. hypogrea probably arose spontaneously by ehromosome doubling from diploid forms. It also seems probable that this took place in the State of Into Grosso, Brisil, which is generally rerognised as place where peanut plants are indigenous. 


\section{LITERATLRA CITADA}

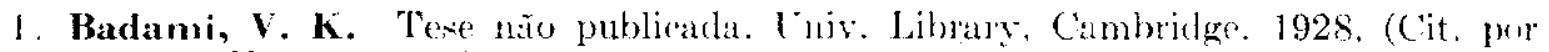
Husted, 1936).

2. Chevalier, Aug. Lorigme botanique et lamelionation des Arachides cultivers. IRev, (le Bot. Appl. et I'Agr. Trop. 9: 97-102. 190-197. 1929.

3. Chevalier, Aug. Monographie de l'Arachide. I. Rev. de Bot. Appl. et D'Agr. Trop. 13: $689-789.1933$.

1. Gaiser, L. O. Claromosome numbers in Angromperns. IV. Bibl. Ciencitica 10: $107-250.1933$.

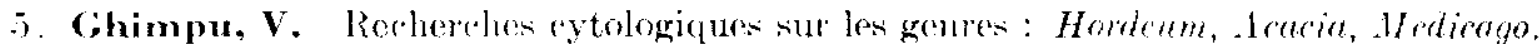
Titis et Queitus. Areh. d'Anat. Mierose. 26: 135-250. Pl. 1-.-VI. 1930.

6. Hayes, $\mathbf{T}$. R. The elassification of groundnut varicties. (With a preliminary note on the inheritance of some characters). Trop. Agr. 10: 318-327. 1933.

7. Hoehne, F. C. Contribuição ao compecimento dá leguninosas da Ronâninit. Comiss. de Linhas Telegr. Wistratég. de M. Grosso alo Amazonats. Publ. n." 74. Anexo 11." 5. Histólia Natural Botânica. Parte XII. Págx. 1-2x. T’úb. $178-192.1922$.

s. Hoehne F. C.. Leguminosas-Papilionadas. Gênero: Arachis. Preedido da Chave Geral para as sub-famílias, tribos e gêneros das leguminosas do Bratil. Flora Brasiliea (Vol. XXV, II : 122); 1 20: 15 táb. 1940.

9. Hoehne, F. C. I Dus novas espécies de Leguminosas do Prasil. Arq. de Bot. do listado de Sino Paulo 2: 15-18. 2 táb. 1944.

10. IIull, Fred. H. Inheritane of rest period of seeds and certain other chatroters in the peanut. Florida Agr' Hxp. Sta., 'lechn. Bull. 314: 1-46 1937.

11. Husted. Ladley. Chromosome number in species of peanut Arachis. Amer. Naturalist $65: 176-477.1931$.

12. Husted, Ladley. Cytological studies on the Peanut, Ararhis. I. Chromosome number and morphology. Cytologia 5: 109-117. 1933.

13. Husled, ladley. Cytologieal Studies on The Peanut Arachis. II - Chromosome number. morphology and behavior, and their aplication to the problen of the origin of the 'ultivated forms. Cytologia $7: 396-423.1936$.

14. Ilusted, Ladley. Etudes eytologiques wu l'Arachide. Rev. Bot. Appl. ot i)'Agr. Trop. 18: 195-197. 1938.

15. Kawakami, J. Chromosome numbers in Leguminosas. 13ot. Mag. (Tokro) 11 : 319-328. 1930. (Cit. por Gaiser, 1933).

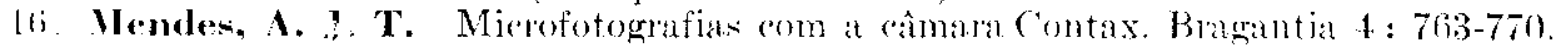
$14+4$.

17. Veme, Y. A. e.s. C. Sampaio o Amendoim. Bol. Seer. da Agr. Ind. "Coni, do li. S. Paulo. 1-32, 1943.

18. Patel, J. S., C. M. John and C. R. Seshadri. The inheritanee of chataters in the groundnut Arachis hypogxa. Proc. Indian Acad. Sr.j. : : 214-233. 1936 .

19. Randolf, L. F. A new fixing and a revised sebedule for the paralfin mothod in plant rytology. Stain Technology 10:95-96. 1935.

20) Stockes, W. F. and Fred H. Ifull Peanut breeding. Jour. Anor. Suc. Agron. 22: $1004-1019.1930$.

\section{DESCRICTO DAS FIGLRAS DA ESTAMIP 6}

Vre. 1 - Arachis marginato Gardn var. smbmaginata Iroehne. Nicrofotogratia de luma metáfase somatica em ponta do rais. 2n=20. 2140x.

Ftr. 2 - Desenho à câmara clara da figurat anterior, com o mesmo anmento.

Fri. 3 - 1rachis hypogar I. (Variedade 11."2). Nierofotografia de uma metáfise somática em ponta de raiz. $2 \mathrm{n}=40.2140 \mathrm{x}$.

Frg. 4 - Desenho ì câmara clara da figura anterior, com o mesmo aumento.

Fu. 5.. Arachis hypogae L. var. "Roxo" (11." 40). Plinta de natureza quimeriual $(2 n=40$ e 80$)$. Nierofotografia de uma metáfises somática, em ponta de raì, na parte mutada. $2 \mathrm{n}=80.2140 \mathrm{x}$.

Fur. 6 - Desenho ì cimmara clara da figura anterios, am o mesmo aumento. 

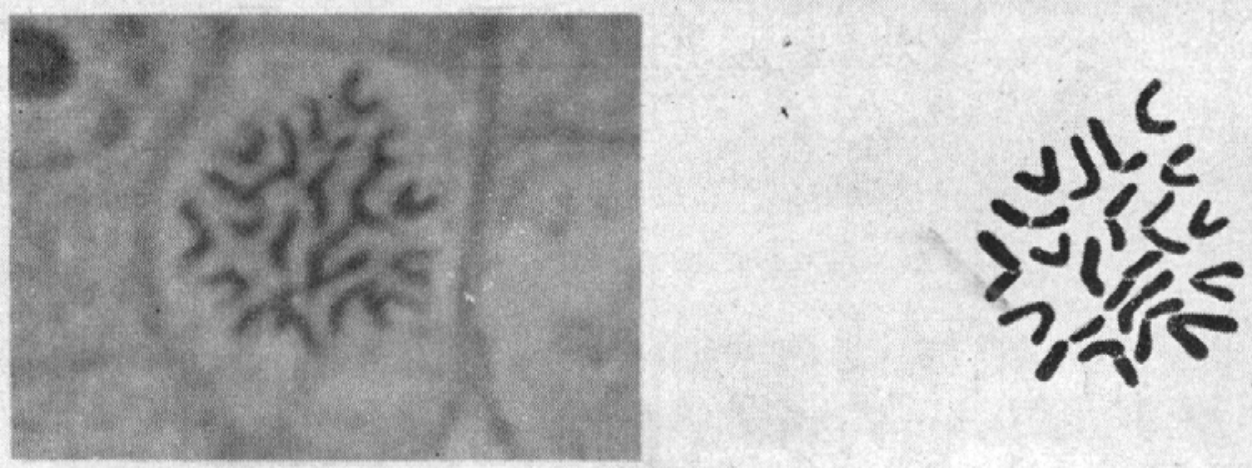

Fị़ 1

Fis? 2
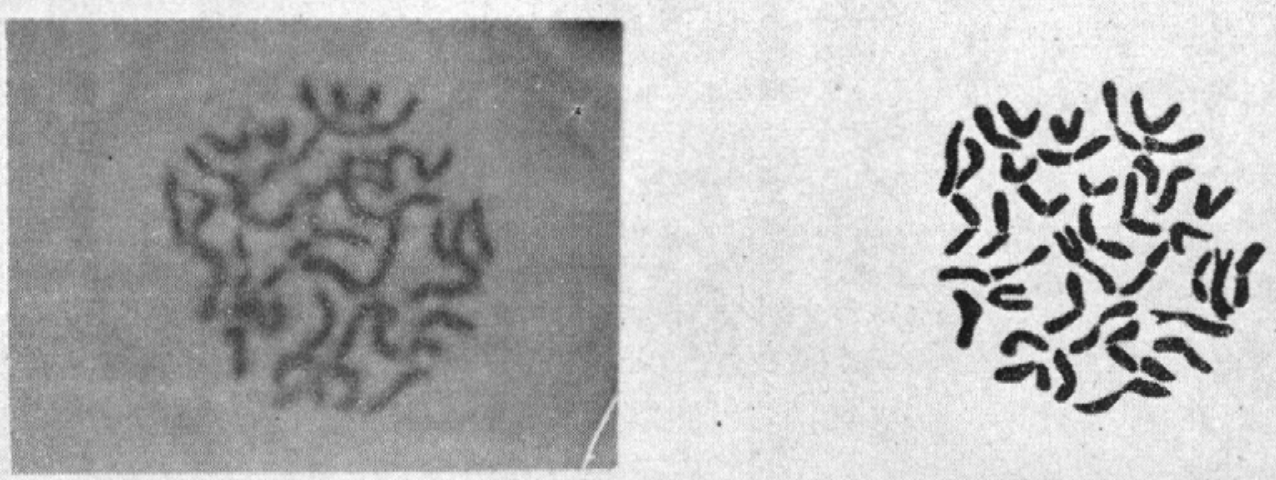

Fiģ 3

Fiģ 4
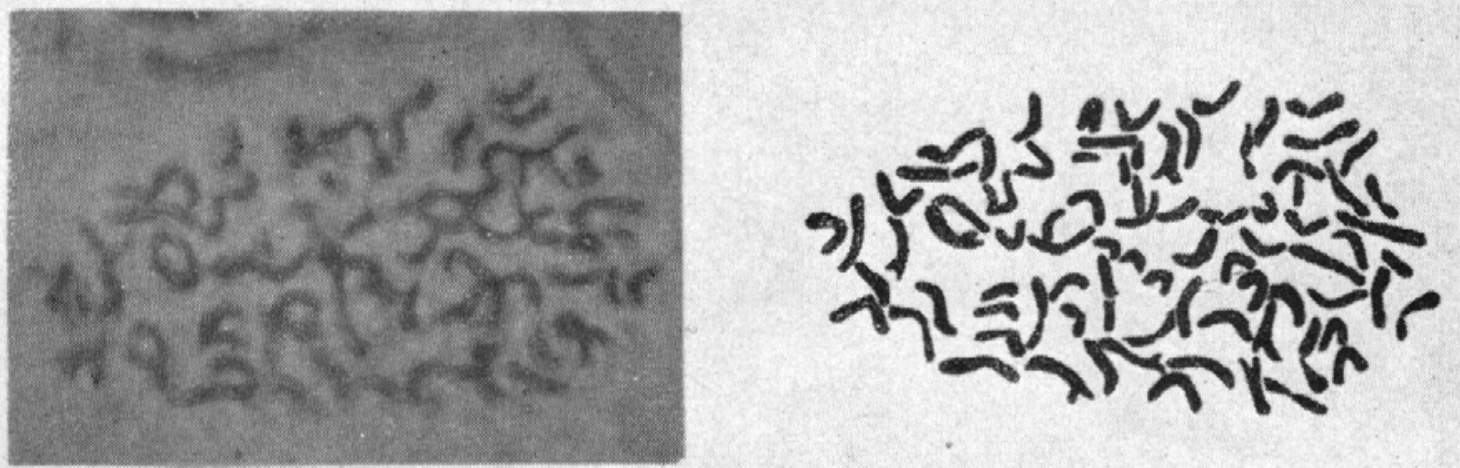

Fiํ 5

Fig. 6 